Vol. 8, Issue 7, July 2021

DOI: 10.17148/IARJSET.2021.8784

\title{
Design And Analysis of Marine Propeller Using Computational Fluid Dynamics
}

\author{
Dr.R.Mani,M.E,Ph.D ${ }^{1}$, R.Gobiraj², M.Mohamed Abbas ${ }^{3}$, .K.Kirubakaran ${ }^{4}$ \\ Professor, KSR Institute for Engineering and Technology, India ${ }^{1}$ \\ UG Students Department of Mechanical,KSR Institute for Engineering and Technology, India ${ }^{2,3,4}$
}

\begin{abstract}
This paper investigates the modelling and hydro dynamic analysis of sub merged marine propellers. The model analysis is based on the computational fluid dynamics (CFD) using fluent software. The method of meshing and the effect of mesh size are studied in this paper. Moreover, different propeller models and methods are explained; and the best setting for obtaining the accurate result are presented. The performance curve of the propeller obtained by CFD are compared and verified with the analytical result. The pressure and velocity contours around the propeller also presented.
\end{abstract}

Keywords: propeller,CFD,hydro dynamic

\section{INTRODUCTION}

A marine propeller is normally fitted to the stem of the ship where it operates in water that has been disturbed by the ship as it moves ahead. A propeller that revolves in the clockwise direction (viewed from front) when propelling the ship forward is called a right-hand propeller. When a propeller is moved rapidly in the water then the pressure in the liquid adjacent to body drops in proportion to the square of local flow velocity. If the local pressure drops below the vapour pressure of surrounding liquid, small pockets or cavities of vapour are formed. Then the flow slows down behind the object and these little cavities are collapsed with very high explosive force. If the cavitation area is sufficiently large, it will change the propeller characteristics such as decrease in thrust, alteration of torque, damage of propeller material (corrosion and erosion) and strong vibration excitation and During recent year's great advancement of computer performance, Computational Fluid-Dynamics (CFD) methods for solving the Reynolds Averaged NaviesStokes (RANS) equation have been increasingly applied to various marine propeller geometries. While these studies have shown great advancement in the technology, some issues still need to be addressed for more practicable procedures. These include mesh generation strategies and turbulence model selection. With the availability of superior hardware, it becomes possible to model the complex fluid flow problems like propeller flow. A ship can be fitted with one, two and rarely three propellers depending upon the speed and maneuvering requirements of the vessel.

A propeller is a type of fan that transmits power by converting rotational motion into thrust. A pressure difference is produced between the forward and rear surfaces of the air foil-shaped blade, and a fluid (such as air or water) is accelerated behind the blade. Propeller dynamics can be modelled by both Bernoulli's principle and Newton's third law. A marine propeller is sometimes colloquially known as a screw propeller or screw.foil-shaped blade, and a fluid (such as air or water) is accelerated behind the blade. Propeller dynamics can be modelled by both Bernoulli's principle and Newton's third law. A marine propeller is sometimes colloquially known as a screw propeller or screw.

Ships propellers come in various shapes and sizes. These range from different shaped blades, thickness, size and angle. Moreover, the number of blades attached to the hub can make a variance in the flow and hence lift. Three blades are usually compromise between balance, blade area and efficiency. More than three blades help reduce the vibration and are often used on larger ships. However, the ideal amount of propeller blades is one, but is very unbalanced and generally not used. Propellers are effectively a simple design and only have a few key components. The hub is the center piece which when sufficiently strong holds the blades in place. The blades are curved in order to slice the water (leading edge) and Provide lift to move the ship forward. The blade face which can be seen from the aft of the ship is at high pressure. The blade back, which is in the direction of the ships' motion, is the low-pressure side. 


\section{International Advanced Research Journal in Science, Engineering and Technology}

Vol. 8, Issue 7, July 2021

DOI: 10.17148/IARJSET.2021.8784

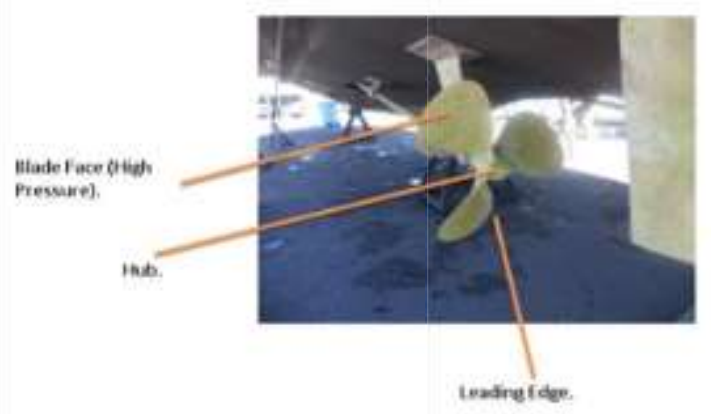

Fig. 1 Image of Fixed 3-Blade Propeller

\section{II.MODELLING}

The CAD software consists of the computer programs to implement computer graphics on the system plus application programs to facilitate the engineering functions of the user company. Examples of these application programs include stress-strain analysis of components, dynamic response of mechanisms, heat-transfer calculations, and numerical control part programming. Computer-aided manufacturing (CAM) can be defined as the use of computer systems to plan, manage, and control the operations of manufacturing plant through either direct or indirect computer interface with the plant's production resources.

\section{DESIGN AND ANALYSIS}

\section{A.Design}

Creo parametric is a solid modeler-it develops models as solids, allowing us to work in a three-dimensional environment. In Creo parametric, the solid models have volumes and surface areas.As a solid modelling tool,Creo parametric is feature-based, associative and parametric

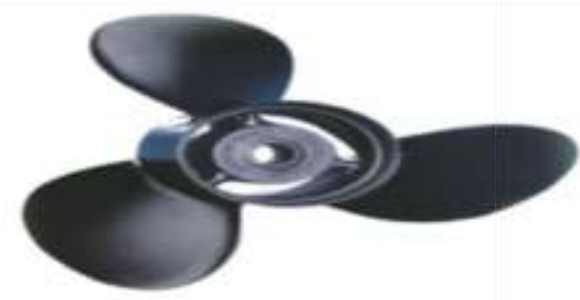

Fig. 2 Marine propeller

CATIA software is also used for a model once a design model is created, it is converted to IGES model or PARASOLID model, to import them in ANSY. Surface designs cannot be displayed in ANSYS software It includes the use of mesh generation techniques for dividing a complex problem into small elements, as well as the use of software program coded with FEM algorithm.

\section{B. Analysis}

In mathematics, the finite element method (FEM) is a numerical technique for finding approximate solutions to boundary value problems for partial differential equations. The problems in a design can be solved, identified and calculated using ANSYS software. It is used for analyzing various analysis like, load, thermal and CFD factors.

\section{Meshing}

Meshing is a general purpose, intelligent, automated highperformance product. It produces the most appropriate mesh for accurate efficient Multiphysics solutions. 
Vol. 8, Issue 7, July 2021

DOI: $10.17148 /$ IARJSET.2021.8784

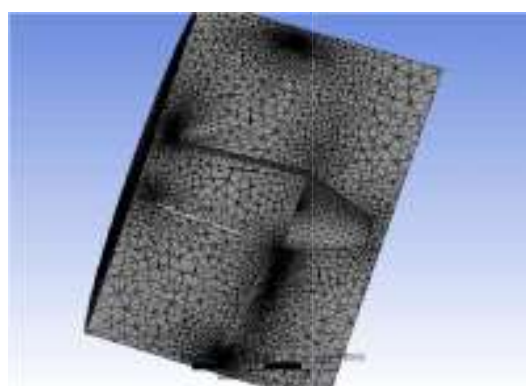

Fig. Meshing

A mesh will be suited for a specific analysis that can be generated for analysis.ANSYS meshing chooses the most appropriate options based on the analysis type and the geometry of the model.Meshing can be done to increase the accuracy in the reports.

\section{Computational Fluid Dynamics (CFD)}

Computational Fluid Dynamics (CFD) is the simulation of fluids engineering systems using modelling (mathematical physical problem formulation) and numerical methods (discretization methods, solvers, numerical parameters, and grid generations, etc.) It is useful in a wide variety of applications and here we note a few to give you an idea of its use in industry. The simulations shown below have been performed using the FLUENT software. It is used to stimulate flow over vehicle. It can be used to study the interaction of propellers or rotors. Bio-medical engineering is a rapidly growing field and uses CFD to study the circulatory and respiratory systems.

\section{REPORTS OF MARINE PROPELLER A. Velocity for 3-Blade Propeller}

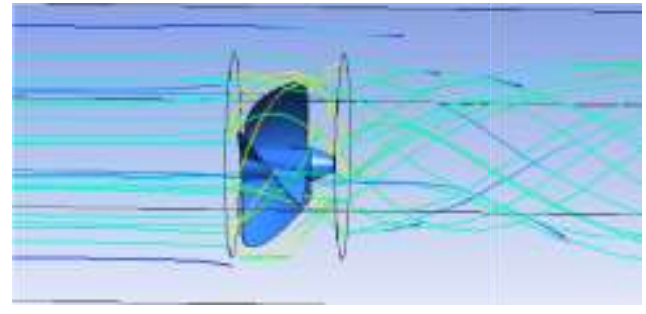

Fig. 4 Velocity for Angle 60

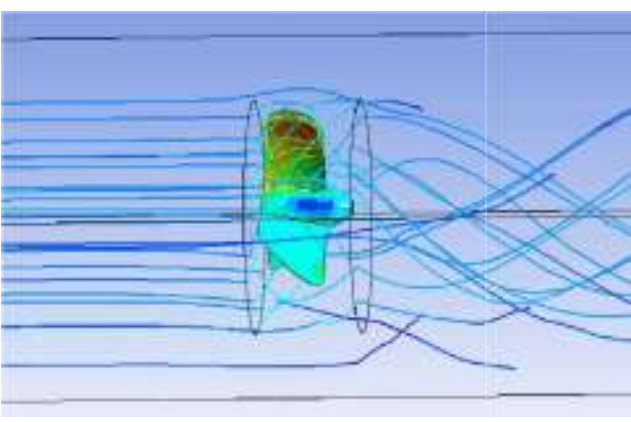

Fig. 5 Velocity for Angle 45 


\section{B. Pressure for 3-Blade Propeller}

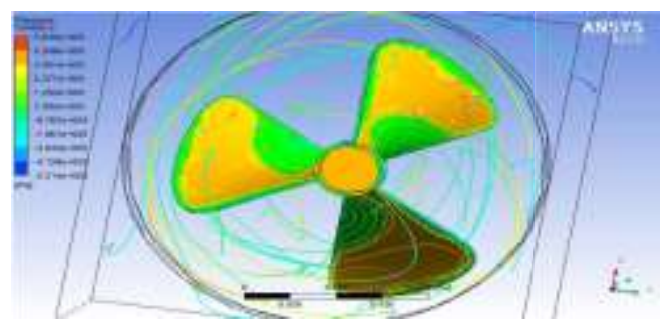

Fig.6 Pressure for Angle 60

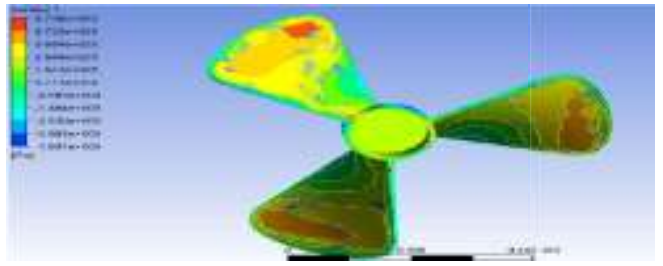

Fig.7 Pressure for Angle 45

\section{CONCLUSION}

Every material has different pressure levels at different stages. The maximum pressure of 60 degree of aluminium blade in water is $5.63 * 105$. The minimum pressure of aluminium in water is $-5.24 * 105$. This pressure value is used to know the withstanding capacity of material for the given input value. This project helped us to know the periodic steps in completing a project work. Thus we have completed the project successfully.

\section{ACKNOWLEDGEMENTS}

I Would Like to express my thanks of gratitude to my Mechanical professor and Dr.R.Mani,M.E,Ph.D. For their able guidance and support in completing my project.I Would also like to extend my gratitude to the principle Dr.M.Venkatesan for providing me with all the facility that was require.

\section{REFERENCES}

[1]. S. Subhas, V.F. Saji, S. Ramakrishna, H.N. Das, "CFD Analysis of a Marine Propeller Flow and Cavitation", International Journal of Computer Applications (0975-8887) volume55-No.16.October 2012

[2]. Xiao Wang, Keith walters, "CFD of Marine-Propeller Performance Using Transition-Sensitive Turbulence Modeling", Journal of Fluid engineering volume 134/ 071107-1 on July 2012

[3]. Liu, Z. and Young, Y.L., 2007. Utilization of deformation coupling in self-twisting composite propellers. Proceedings of 16th International Conference on Composite Materials, Kyoto, Japan, 8-13 July 2007.

[4]. Kerwin, J.E., Kinnas, S.A., Lee, J.T. and Shih, W.Z., 1987. A surface panel method for the hydrodynamic analysis of ducted propellers. Transactions of Society of Naval Architects and Marine Engineers, 95, pp.93-122.

[5]. Hyoungsuk Lee, Min-Churl Song, Jung-Chun Suh and Bong-Jun Chang. Hydro-elastic analysis of marine propellers based on a BEM-FEM coupled FSI algorithm. Int. J. Nav. Archit. Ocean Eng. (2014) 6:562 577.

[6]. Veeranagouda Patil, H. R. Purushothama, A. Manjunatha and Vijay Kumar Mishra. Performance Evaluation of Marine Propeller using Numerical Simulation. Indian Journal of Science and Technology, Vol 9(45), DOI: 10.17485, December 2016.

[7]. M.P. Kishore, R.K. Behera, Numerical Investigation for CFD Simulation of Open Water Characteristics and Cavitation Inception of Marine Propeller Blade, Journal OF Maritime Research, ISSN: 1697-4040, Vol XIII. No. XI (2014) pp 71-76. 